\title{
Tribological Behavior of HVOF Cermet Coatings as Alternative to Cr-Plating in Artificial Salt-Fog Atmosphere
}

\author{
Zhang Jifu, Liu Min, Zhou Kesong, Deng Changguang, Deng Chunming, Song \\ Jinbing
}

National Engineering Laboratory for Modern Materials Surface Engineering Technology, the Key Laboratory of Guangdong for Modern Surface Engineering Technology, Guangdong Institute of New Materials, Guangzhou 510650, China

\begin{abstract}
Two kinds of cermet coatings (WC-10Co4Cr and $\mathrm{Cr}_{3} \mathrm{C}_{2}-\mathrm{NiCr}$ ) were prepared by high velocity oxygen fuel (HVOF) to enhance the wear- and corrosion-resistance of key components in aviation and marine fields. Their tribology behavior in salt-fog condition were studied by a reconstructive friction testing machine equipped with artificial salt-fog spraying apparatus. Traditional chrome plating (Cr-plating) was also researched for comparison. The results show that different coating display different wear-mechanisms. Cr-plating exhibits mainly adhesive-wear mechanism, however, the WC-10Co4Cr coatings displays mainly abrasive-wear mechanism, while the $\mathrm{Cr}_{3} \mathrm{C}_{2}-\mathrm{NiCr}$ coating shows both mechanisms of adhesive-wear and abrasive-wear. Salt-fog atmosphere has important effects on tribological behavior of the coatings, which reduces the friction coefficient and corrosion loss of the coatings, resulting in the wear-mechanism of WC-10Co4Cr coating change to oxidation/ corrosion wear.
\end{abstract}

Key words: cermets coating; tribological behavior; salt-fog atmosphere; wear mechanism

The marine environment is a very harsh natural environment characterized with high-humidity, high temperature, and high corrosion, but it is also the main fields of human activities. We should take the wear resistance behavior into account for the key rotatable parts of aircraft or ship serving in marine environments in the meantime, we should pay more attention to the corrosion resistance $\mathrm{e}^{[1]}$.

Hard chromium (Cr-plating) technique is so far one of the most effective methods to coat various critical mechanical components, such as valves, pistons, rods, and hydraulic components, due to its well corrosion- and wear-resistance behavior. Unfortunately, Cr-plating process will cause bad effects on human health because some toxicological substances have to be used in the galvanic process, resulting in the risk of cancer ${ }^{[2]}$.

Compared to the electroplating process, dry surface treatment is much less toxic, such as physical vapor deposition (PVD) and thermal spraying. Among the advanced thermal spraying techniques, high velocity oxygen fuel (HVOF) spaying is an important surface treatment, which is widely used in various fields, especially for work-piece is needed to serve in the heavy abrasion, the high temperature and the corrosion condition ${ }^{[3-5]}$. For the sprayed-materials, carbide cermets powder such as $\mathrm{WC}^{[4]}$ and $\mathrm{Cr}_{3} \mathrm{C}_{2}{ }^{[6]}$, have been proved to possess an excellent comprehensive performance of good corrosion resistance, brightness, and interesting mechanical properties. And those materials have been widely used in aerospace, marine and automotive industries.

From the viewpoint of tribology, the environment atmosphere, such as air, vacuum and corrosion medium have important effects on tribological behavior of the material. Many reports have focused on the wear behavior

Received date: October 25, 2015

Foundation item: National Natural Science Foundation of China (51101038)

Corresponding author: Zhang Jifu, Ph. D., Senior Engineer, Guangdong Institute of New Materials, Guangzhou 510650, P. R. China, Tel: 0086-20-61086656, E-mail: jfzhang123@c163.com

Copyright () 2016, Northwest Institute for Nonferrous Metal Research. Published by Elsevier BV. All rights reserved. 
of HVOF carbide ceramic coatings in atmosphere, water, sea water and acid corrosion medium ${ }^{[7-10]}$. However, there is few reports on the wear behavior of carbide ceramic coatings in salt-fog atmosphere. Since salt-fog atmosphere is a typical environment for many key components coated with carbide ceramic coatings severed in marine, study of wear mechanism of materials at the atmosphere is significant to design and select better coating material for key components.

Therefore, we studied the wear behavior of $\mathrm{WC}$ and $\mathrm{Cr}_{3} \mathrm{C}_{2}$ cermets coatings in artificial salt-fog atmosphere in the present paper. Finally, we achieved a rapid evaluation of various coatings in keys components in marine environment.

\section{Experiment}

316L stainless steel with nominal chemical composition (wt\%) of $0.08 \mathrm{C}, 1.0 \mathrm{Si}, 2.0 \mathrm{Mn}, 0.035 \mathrm{P}, 1.0 \sim 14.0 \mathrm{Ni}$, 16.0 18.5 $\mathrm{Cr}$ and balance of $\mathrm{Fe}$ was used as a substrate. Prior to thermal spraying process, square $(110 \mathrm{~mm} \times 110$ $\mathrm{mm} \times 7 \mathrm{~mm}$ ) samples were degreased with acetone and grit blasted with $\mathrm{Al}_{2} \mathrm{O}_{3}$ (grade 46\#).

$\mathrm{Cr}_{3} \mathrm{C}_{2}-\mathrm{NiCr}$ and $\mathrm{WC}-10 \mathrm{Co} 4 \mathrm{Cr}$ coatings were obtained by HVOF using a GTV $\mathrm{K}_{2}$ system, with oxygen and kerosene to partially melt the powder particles and spray them onto the steel substrate. The selected powders were commercial $\mathrm{Cr}_{3} \mathrm{C}_{2}-\mathrm{NiCr}$ and $\mathrm{WC}-10 \mathrm{Co} 4 \mathrm{Cr}$. More details of the powders are shown in Table 1.

In the process of spraying, the substrate temperature was controlled by compressed air and optimum spraying parameters were taken to deposit the coatings with uniform distribution and thickness. The deposited coatings were about $0.3 \mathrm{~mm}$ in thickness. At the same time, Cr plating was prepared by traditional plating process with thickness of 0.1 $\mathrm{mm}$. After the spraying process, small square samples of 45 $\mathrm{mm} \times 45 \mathrm{~mm} \times 6 \mathrm{~mm}$ were cut and polished to surface roughness of $R_{\mathrm{a}}=0.1 \mu \mathrm{m}$ using a diamond abrasive paper for friction wear testing.

Friction wear tests in artificial salt-fog atmosphere were performed by a MMW-1A friction testing machine as shown in Fig.1. Friction wear tests used the ball-disc friction contact way. The coating samples were placed on the pedestal for testing. The friction pair was $\mathrm{Si}_{3} \mathrm{~N}_{4}$ ceramic ball. In order to create an atmosphere of salt-fog, salt-fog box was set up on the friction area spraying with $5 \% \mathrm{NaCl}$ solution.

The surface morphology and composition of wear-scar

Table 1 Thermal spraying powders for $\mathrm{Cr}_{3} \mathrm{C}_{2}-\mathrm{NiCr}$ and $\mathrm{WC}$ $10 \mathrm{Co} 4 \mathrm{Cr}$

\begin{tabular}{ccc}
\hline Powder composition & Provider (H.C. Starck) & Particle size/ $\mu \mathrm{m}$ \\
\hline $\mathrm{Cr}_{3} \mathrm{C}_{2}-\mathrm{NiCr} / 75-25$ & AMPERIT 588.074 & $-45 /+15$ \\
$\mathrm{WC}-10 \mathrm{Co} 4 \mathrm{Cr} / 86-10-4$ & AMPERIT 558.074 & $-45 /+15$ \\
\hline
\end{tabular}

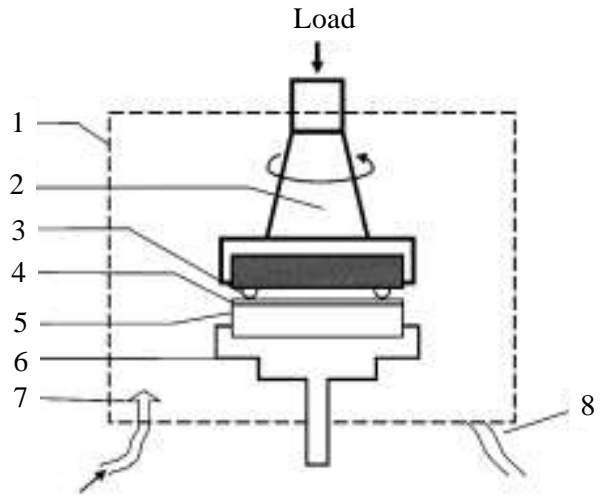

1-salt-fog box, 2-chuck jaw, 3-friction pair, 4-coating, 5-substrate, 6-substrate chuck, 7-fog sprayer, 8-leakage fluid dram

Fig.1 Sketch of the apparatus used for tribo-corrosion tests

were characterized by JMS-5910 scanning electron microscope (SEM) and energy dispersive X-ray spectrometry (EDAX), respectively. In the process of tests, the fluctuation of friction coefficient was supervised and displayed in computer master program. The wear extent of the samples was obtained by weighing quality change before and after the test. The weighing equipment was electronic analytical balance with accuracy of $0.1 \mathrm{mg}$. The wear-rate of the sample was calculated by the following formula ${ }^{[11]}$ :

$$
W=\frac{\Delta W}{2 \pi \operatorname{Rtn} \mu N}
$$

where, $\Delta W$-wear mass loss (mg), $R$-average radius of grinding crack $(\mathrm{m}), t$-friction time $(\mathrm{s}), n$-friction rotating speed (r/min), $N$-load force on the friction sample $(\mathrm{N}), \mu$ friction coefficient. The wear-rate means wear mass loss by the unit friction energy.

\section{Results and Discussion}

\subsection{Structural characterization}

The cross-section morphologies of various coatings are shown in Fig.2. We can see the micro-cracks inevitably exists in the Cr-plating (Fig.2a), which may be the channel of corrosive medium when the coating serves in marine environment for a long-term ${ }^{[12]}$. Both the $\mathrm{WC}-10 \mathrm{Co} 4 \mathrm{Cr}$ and $\mathrm{NiCr}-\mathrm{Cr}_{3} \mathrm{C}_{2}$ coatings prepared by HVOF are good adhesive to the base, but micro-pores caused by spraying process are inevitable in the coating. However, those micro-pores in the spray coatings are isolated rather than through holes in Cr-plating. The micro-hardness $\mathrm{HV}_{300 \mathrm{~g}}$ test of various coatings indicates that the hardness is $7770 \pm 40 \mathrm{MPa}$ for Cr-plating, $10020 \pm 1420 \mathrm{MPa}$ for $\mathrm{NiCr}-\mathrm{Cr}_{2} \mathrm{C}_{3}$ coating, and $12460 \pm 1120 \mathrm{MPa}$ for $\mathrm{WC}-10 \mathrm{Co} 4 \mathrm{Cr}$ coating.

\subsection{Effect of salt-fog condition on the friction character}

Fig. 3 shows the fluctuation of friction coefficients of 


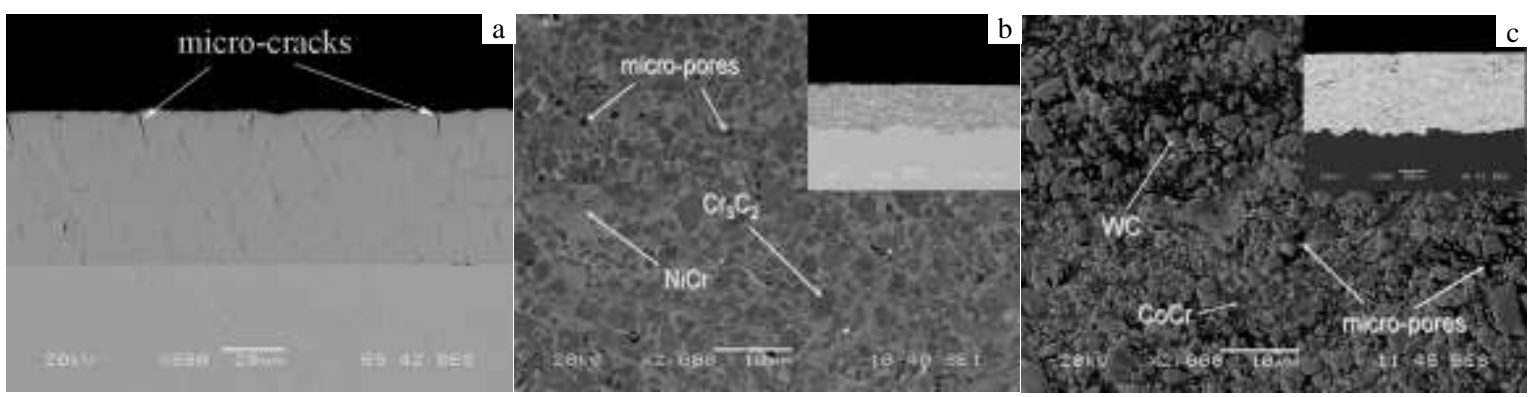

Fig.2 Cross-section morphologies of various coating samples: (a) Cr-plating, (b) $\mathrm{NiCr}-\mathrm{Cr}_{3} \mathrm{C}_{2}$, and (c) WC-10Co4Cr
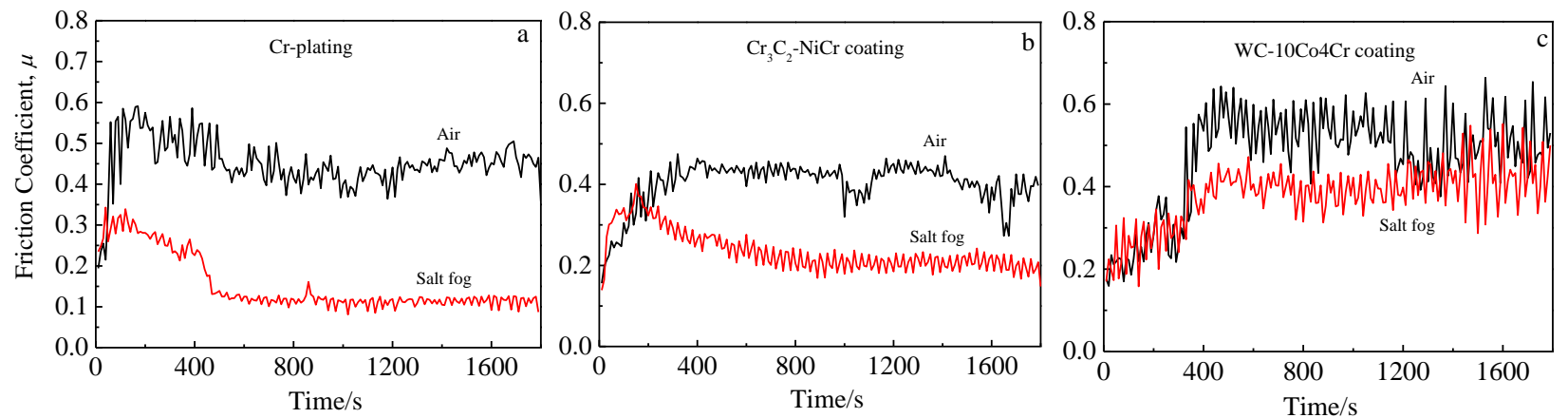

Fig.3 Friction coefficient $\mu$ of various coating samples in dry-air atmosphere and salt-fog atmosphere: (a) $\mathrm{Cr}-\mathrm{plating},(\mathrm{b}) \mathrm{Cr} \mathrm{C}_{2}-\mathrm{NiCr}$ coating, and (c) WC-10Co4Cr coating

Cr-plating, $\mathrm{Cr}_{3} \mathrm{C}_{2}-\mathrm{NiCr}$ and $\mathrm{WC}-10 \mathrm{Co} 4 \mathrm{Cr}$ coating in dry-air atmosphere and salt-fog atmosphere. It is indicated that friction coefficient $(\mu)$ of three kinds of coatings decreases under salt-fog condition compared to that under dry-air condition. It is found that the samples' surface is wet for a time of test under salt-fog atmosphere, so thin liquid film (TL-film) may be formed on the surface of samples, which has played a certain liquid lubrication role for the samples. So the $\mu$ of the samples in salt-fog atmosphere is lower than that in dry-air condition.

Wear-scar morphologies of various coatings were observed by SEM as shown in Fig.4. It indicates a lot of abrasive dust is adhesive to the wear-scar of Cr-plating after attrition (Fig.4a), which is in conformity with typical characteristics of adhesive-wear mechanism ${ }^{[13]}$. It is commonly believed that when adhesive-wear occurs, some plastic deformation points first form at frictional contact interface, and then those points grow up along the direction of motion and shear fracture appears. Back and forth, new plastic deformation points form and shear fracture happens. So wear-scar surface is full of sheared nodes, which form the specific morphology of adhesive-wear.

Another very different situation is that a large amount of furrows is formed on the wear-scar of WC-10Co4Cr coating
(Fig.4c), which can be understood as abrasive-wear mechanism ${ }^{[14]}$. Since WC-10Co4Cr coating is composed of WC hard-particles and $\mathrm{CoCr}$ binding-particles, hard particles of WC will peel off from the coating as rigid particles in the friction process, resulting in the furrows-like morphology ${ }^{[15,16]}$.

In addition, the wear-scar morphology of $\mathrm{Cr}_{3} \mathrm{C}_{2}-\mathrm{NiCr}$ coating is the combination of the Cr-plating and WC-10Co4Cr (Fig.4b). The $\mathrm{Cr}_{3} \mathrm{C}_{2}-\mathrm{NiCr}$ coating is also composed of hard-particles $\left(\mathrm{Cr}_{3} \mathrm{C}_{2}\right)$ and binding-particles $(\mathrm{NiCr})$, so furrows-like morphology occurs in the wear-scar. But the hardness of $\mathrm{NiCr}$ phase is relatively low, and hard particles of $\mathrm{Cr}_{3} \mathrm{C}_{2}$ will peel off from the coating as rigid particles in the friction process, so the coating exhibits both the adhesive-wear and abrasive-wear mechanism.

\subsection{Effect of load on wear mechanism in salt-fog atmosphere}

\subsubsection{Wear mechanism of Cr-plating}

To further clarify the salt-fog atmosphere influence on coating tribological behavior, various coating samples were tested in salt-fog atmosphere by changing the load. Fig.5 shows that $\mu$ of $\mathrm{Cr}$-plating changes under different load conditions. Under the load of $100 \mathrm{~N}$, the $\mu$ is stable, about 0.1 , when the load increases to $200 \mathrm{~N}$, the $\mu$ increases 


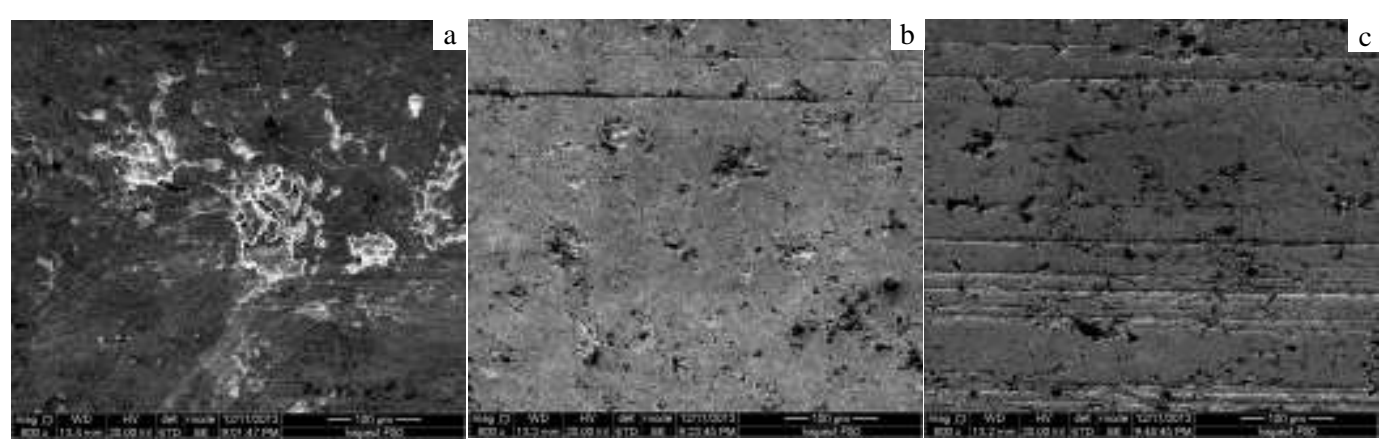

Fig.4 Surface morphologies of wear-scar of various coating samples: (a) Cr-plating, (b) $\mathrm{Cr}_{3} \mathrm{C}_{2}$ - $\mathrm{NiCr}$, and (c) WC-10Co4Cr

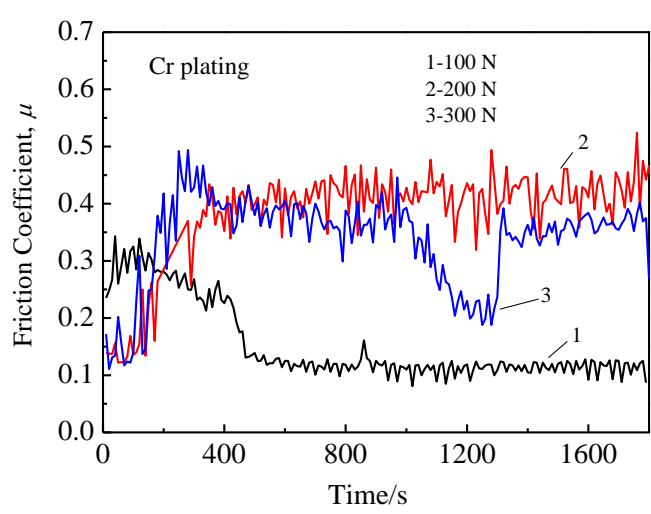

Fig.5 Friction coefficient $\mu$ of Cr-plating under different loads in salt-fog atmosphere

significantly to about 0.42 . But when the load increases to $300 \mathrm{~N}$, the $\mu$ almost does not change any more.

Fig.6 shows effect of the load on wear-rate in dry-air and fog-salt atmosphere. Under the dry-air atmosphere, the wear-rate increases significantly with the increasing of load, while the wear-rate does not change too much when the load increases under salt-fog atmosphere.

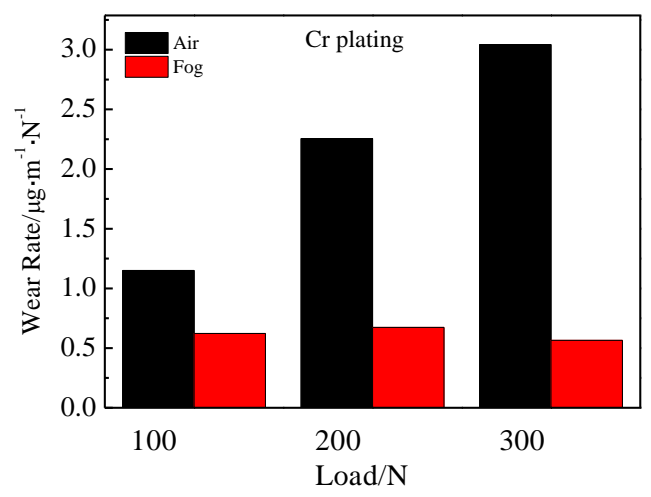

Fig.6 Effect of load on the wear-rate of Cr-plating
Based on the analysis in section 2.2, the tribology behavior of Cr-plating can be explained as follows: the wear behavior of Cr-plating complies with the rule of adhesive-wear mechanism in dry-air atmosphere, so the magnitude of the abrasion is increased with the increasing of load. But under the fog-salt atmosphere, besides adhesive-wear, the lubrication effect of TL-film on frictional interface is notable, so wear-rate is relatively low. When the load increases, the extrusion of frictional ball on the coating is serious and adhesive-wear mechanism is predominant in Cr-plating, so $\mu$ of Cr-plating does not change, which is similar to that tested under dry-air atmosphere (Fig.3a).

\subsubsection{Wear mechanism of $\mathrm{Cr}_{3} \mathrm{C}_{2}-\mathrm{NiCr}$ coating}

Unlike Cr-plating, the $\mu$ of $\mathrm{Cr}_{3} \mathrm{C}_{2}-\mathrm{NiCr}$ coating changes little when the load increases as shown in Fig.7. It implies that $\mathrm{Cr}_{3} \mathrm{C}_{2}-\mathrm{NiCr}$ coating may follow the same wear-mechanism when the load changes, namely the double failure mechanism of both adhesive-wear and abrasive-wear as set forth in Fig.3b.

Fig. 8 shows the influence of the load on wear-rate of $\mathrm{Cr}_{3} \mathrm{C}_{2}$-NiCr coating. It can be seen the wear-rate increases with increasing of the load either in dry-air condition or salt-fog atmosphere. By contrast, the wear-rate in salt-fog atmosphere is much smaller due to the lubrication effect of TL film.

\subsubsection{Wear mechanism of WC-10Co4Cr coating}

Fig. 9 shows the $\mu$ of $\mathrm{WC}-10 \mathrm{Co} 4 \mathrm{Cr}$ is higher under load of $100 \mathrm{~N}$, but when the load increases to 200 and $300 \mathrm{~N}$, the $\mu$ of WC-10Co4Cr declines obviously. Fig.10 shows the highest wear-rate of WC-10Co4Cr coating under load of $200 \mathrm{~N}$ in dry-air condition, which decreases when the load increases to $300 \mathrm{~N}$. But the wear-rate of $\mathrm{WC}-10 \mathrm{Co} 4 \mathrm{Cr}$ coating is lower and lower with increase of the load in salt-fog atmosphere.

The morphology and composition of wear scar of WC-10Co4Cr coating under $200 \mathrm{~N}$ load are analyzed by SEM and EDAX. Fig.11 shows that some chippings have been formed on the surface, and EDAX indicates that 
chippings are composed of $\mathrm{O}$ and $\mathrm{Cl}$ elements, manifesting oxidation or corrosion products has formed on the wear scar under high load. We generally believe that existence of oxidation or corrosion products during the friction interface have the solid lubrication effect ${ }^{[17,18]}$, which plays a role to reduce the friction coefficient of the coating and the wear-rate at high load. So the $\mu$ and wear-rate of $\mathrm{WC}-10 \mathrm{Co} 4 \mathrm{Cr}$ coating do not rise but lower with the load increasing. This phenomenon is beneficial to WC-10Co4Cr protecting key components in marine environment.

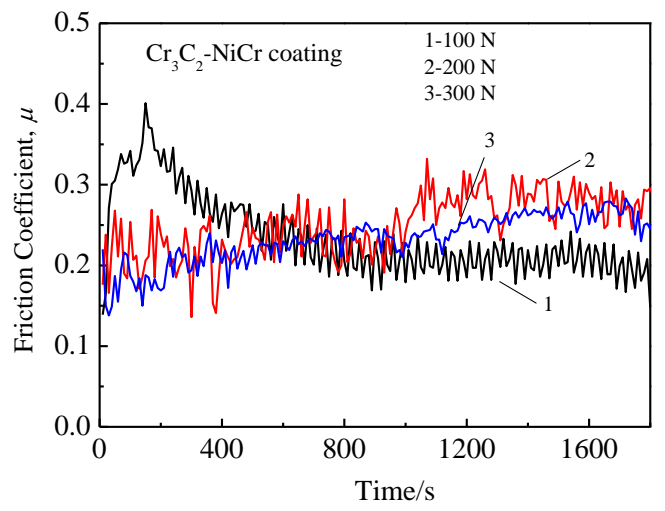

Fig.7 Friction coefficient $\mu$ of $\mathrm{Cr}_{3} \mathrm{C}_{2}-\mathrm{NiCr}$ coating under different loads

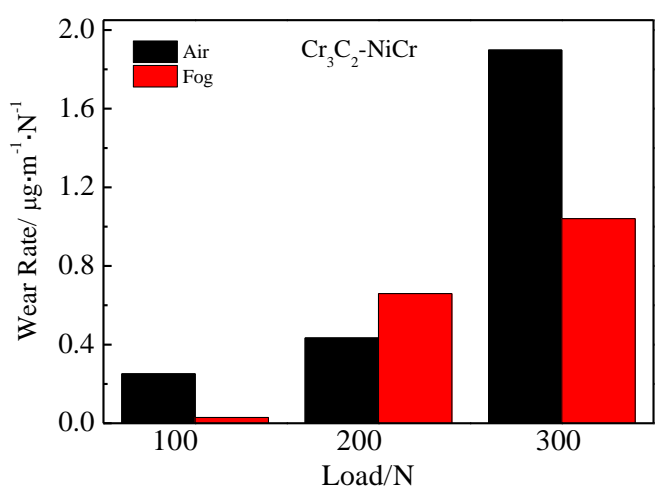

Fig.8 Effect of load on the wear-rate of $\mathrm{Cr}_{3} \mathrm{C}_{2}-\mathrm{NiCr}$ coating

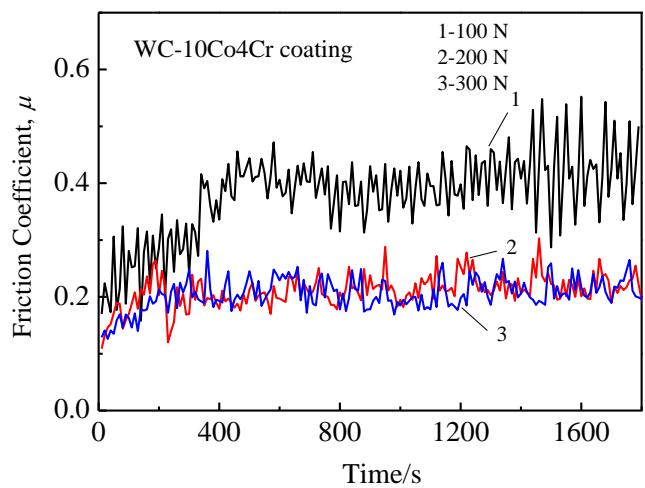

Fig.9 Friction coefficient $\mu$ of WC-10Co4Cr coating under different loads

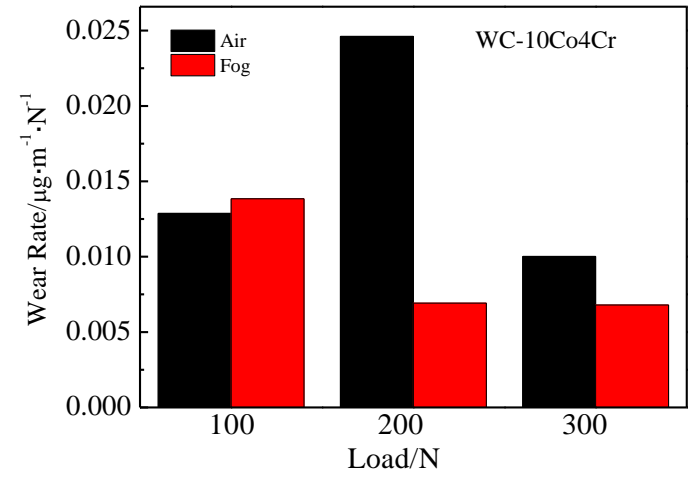

Fig.10 Effect of load on the wear-rate of WC-10Co4Cr coating

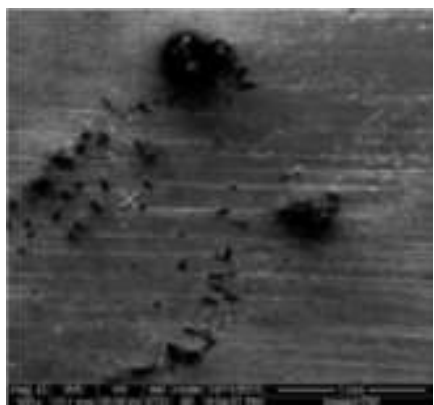

\begin{tabular}{cc}
\hline Element & wt\% \\
\hline $\mathrm{C} \mathrm{K}$ & 11.88 \\
$\mathrm{O} \mathrm{K}$ & 3.48 \\
$\mathrm{Na} \mathrm{K}$ & 9.61 \\
$\mathrm{Cl} \mathrm{K}$ & 14.73 \\
$\mathrm{Cr} \mathrm{K}$ & 2.17 \\
$\mathrm{Co} \mathrm{K}$ & 5.84 \\
$\mathrm{~W} \mathrm{M}$ & 52.3 \\
Total & 100.00 \\
\hline
\end{tabular}

Fig.11 Morphology and composition analysis by SEM and EDAX for wear scar of WC-10Co4Cr coating under $200 \mathrm{~N}$ load

\section{Conclusions}

1) The Cr-plating is mainly characterized by adhesivewear mechanism, WC-10Co4Cr coating is mainly characterized by abrasive-wear mechanism, while $\mathrm{Cr}_{3} \mathrm{C}_{2}$ $\mathrm{NiCr}$ coating exhibits both the adhesive-wear and abrasive-wear mechanism when tested in dry-air.

2) In salt-fog atmosphere, the salt-fog will form a thin liquid film on the surface of the coating, which plays a certain liquid lubrication effect for the coating and reduces the friction coefficient. Increasing the load will change the wear mechanism of various coatings. The Cr-plating shows an adhesive-wear mechanism and lubrication effect by TL-film. The $\mathrm{Cr}_{3} \mathrm{C}_{2}-\mathrm{NiCr}$ coating complied with double failure mechanism of both adhesive-wear and abrasive-wear In addition the wear-mechanism of $\mathrm{WC}-10 \mathrm{Co} 4 \mathrm{Cr}$ changes from abrasive-wear mechanism to oxidation/corrosion wear.

\section{References}

1 Gandra J, Krohn H, Miranda R M et al. Journal of Materials Processing Technology[J], 2014, 214: 1062

2 Sahraoui T, Fenineche N E, Montavon G et al. Journal of Materials Processing Technology[J], 2004, 152: 43

3 Cinca N, Lima C R C, Guilemany J M. Journal of Materials Research and Technology[J], 2013, 2: 75 
4 Wang Q, Xiang J, Chen G et al. Journal of Materials Processing Technology[J], 2013, 213: 1653

5 Guo X, Planche M P, Chen H L J. Journal of Materials Processing Technology[J], 2014, 214: 456

6 Sidhu H S, Sidhu B S, Prakash S. Journal of Materials Processing Technology[J], 2006, 171: 77

7 Zhou K S, Deng C M, Liu M et al. Rare Metal Materials and Engineering[J], 2009, 38(4): 671 (in Chinese)

8 Espallargas N, Berget J, Guilemany J M et al. Surface \& Coatings Technology[J], 2008, 202: 1405

9 Choa J E, Hwang S Y, Kim K Y. Surface \& Coatings Technology[J], 2006, 200: 2653

10 Ding Z X, Tu G F. Journal of Wuhan University of Technology-Materials Science Edition[J], 2004, 19: 52
11 Wang G, Zhang Y, Sanming D et al. Tribology[J], 2007, 27: 346

12 Beyragh M R S, Asl S K, Norouzi S. Surface \& Coatings Technology[J], 2010, 205: 2605

13 Bowden F, Tabor D. Friction and Lubrication of Solids $[\mathrm{M}]$ Cambridge: Clarendon Press, 2001

14 Shipway P H, Hogg J J. Wear [J], 2005, 259: 44

15 Kumari K, Anand K, Bellacci M et al. Wear[J], 2010, 268: 1309

16 Krakhmalev P V, Rodil T A, Bergström J. Wear[J], 2007, 263 : 240

17 Suh N P. Wear[J], 1977, 44: 1

18 Sin H, Saka N, Suh N P. Wear[J], 1979, 55: 16

\title{
超音速火焰喷涂金属陶瓷涂层与电镀硬铬在盐雾气氛下的腐蚀-磨损机制研究
}

\author{
张吉阜，刘 敏，周克崧，邓畅光，邓春明，宋进兵
}

(广东省新材料研究所 现代材料表面工程技术国家工程实验室 广东省现代表面工程技术重点实验室，广东 广州 510650)

\begin{abstract}
摘 要: 为研究碳化物类金属陶瓷涂层在海洋气氛下的抗腐蚀与抗磨损性能, 采用超音速火焰喷涂技术 (HVOF) 制备了WC-10Co4Cr 和 $\mathrm{Cr}_{3} \mathrm{C}_{2}-\mathrm{NiCr} 2$ 种典型的金属陶瓷涂层, 采用自制的盐雾喷射腐蚀-磨损装置, 研究涂层的腐蚀-磨损行为, 同时与传统的硬铬镀层作对 比, 并采用扫描电镜(SEM)、能谱分析(EDAX)等表征试样的腐蚀磨损形貌特征。结果显示, 在干燥大气环境下铬镀层主要表现为黏着一 磨损机制, $\mathrm{Cr}_{3} \mathrm{C}_{2}$ - NiCr涂层同时表现出黏着-磨损与磨粒-磨损机制, 而 WC-10Co4Cr则表现为单纯的磨粒-磨损。施加盐雾气氛后, 试样 表面形成有液态膜, 摩擦系数与磨损量均有所下降。盐雾气氛下增大摩擦副的载荷压力, $\mathrm{Cr}_{3} \mathrm{C}_{2}-\mathrm{NiCr}$ 涂层的磨损量增加很快, 而 WC-10Co4Cr涂层的磨损机制发生转变, 磨损量出现不增反降现象。
\end{abstract}

关键词：金属陶瓷涂层; 摩擦行为; 盐雾气氛; 磨损机制

作者简介: 张吉阜, 男, 1981 年生, 博士, 高级工程师, 广东省新材料研究所, 广东 广州 510650, 电话: 020-61086656, E-mail: jfzhang123@163.com 